\title{
O CONTEXTO DE INFORMAÇÕES SOBRE A EVASÃO ESCOLAR NO ENSINO MÉDIO TÉCNICO NA ARGENTINA
}

\section{THE BACKGROUND OF INFORMATION ON SCHOOL DROPOUT IN VOCATIONAL}

\author{
EDUCATION IN ARGENTINA
}

\author{
Denise Bianca Maduro Silva ${ }^{1}$ \\ Fabrício Aparecido dos Santos 2 \\ Universidade Federal de Minas Gerais, Brasil
}

\begin{abstract}
Resumo: No sentido de aportar para a análise do problema da evasão escolar no ensino médio técnico na Argentina, apresentam-se neste artigo os dados estatísticos educacionais nacionais para esse nível de ensino no ano de 2015, os quais são discutidos em relação a qualidade do dado obtido, e são desagregados por modalidade e sexo, bem como por tipo de oferta. Os valores relativos e absolutos da evasão escolar são contextualizados por meio de entrevistas semiestruturadas com 18 gestores da informação educacional e da modalidade técnico-profissional no país; as evidências são discutidas à luz da literatura sobre o neoinstitucionalismo histórico. Constatou-se que estão em processo de desenvolvimento sistemas de informações capazes de trazer a medida da evasão escolar e elucidar qual a real influência dos fatores escolares a ela associados. Sem informações sistematizadas, o discurso em torno dos fatores associados à evasão escolar pode trabalhar em prol de preconcepções de enraizamento histórico a respeito do ensino médio técnico- como seu mandato seletivo e questões de gênero influenciando o discurso sobre as iniciativas formuladas, negadas ou invisibilizadas no combate à evasão escolar.
\end{abstract}

Palavras-chave: Evasão Escolar; Ensino Médio; Argentina; Educação Profissional; Ensino Médio Técnico.

\begin{abstract}
In order to contribute to the analysis of the problem of dropout in the vocational education in Argentine, this paper presents the national educational statistical data for this level of education in 2015, which are discussed in relation to the quality of the data obtained and disaggregated by modality, gender and also type of offer. The discussion of quantitative data is based on literature on dropout and 18 interviews with managers of educational information and the technical-professional education modality in the country; the evidences are discussed in the light of the historical neoinstitutionalism theory. It was found that are still in the process of

\footnotetext{
${ }^{1}$ Doutora em Educação pelo Doutorado Latino-americano em Educação da UFMG. Mestre em Ciências Sociais com Orientação em Educação pela FLACSO/Argentina. Pedagoga pela UFMG. Técnica em Assuntos Educacionais na Pró-Reitoria de Extensão da UFMG. E-mail: denisebianca@ufmg.br.

${ }^{2}$ Pós doutorando em Física (ICEX/UFMG), doutor em física aplicada a biologia molecular no Instituto de Física de São Carlos(IFSC/USP), mestre em ciência em engenharia de materiais(IFSC/USP) graduado em física aplicada a ciência dos materiais(UFOP).E-mail: fabricio.santos@mediconchip.com.br.
} 
development information systems capable of bringing the school dropout measure and elucidate what is the real influence of school factors associated with it. Without systematized information, the discourse around the factors associated with school dropout can work in favor of historical rooting preconceptions about the vocational school - such as its selective mandate and gender issues - influencing the discourse on the initiatives formulated or denied to combat school dropout.

Keywords: School Dropout; High School; Argentina; Vocational Education; Technical High School.

Recebido em: 06/09/2019

Aprovado em: 11/12/2019

Publicado em: 11/04/2020

\section{INTRODUÇÃO}

A obrigatoriedade do ensino médio ${ }^{3}$, iniciando-se com 12/13 anos e encerrando-se com 17/18 anos, transcorrendo 5/6 anos de formação, foi determinada na Argentina em 2006, pela Lei 26.206 ou Lei de Educação Nacional - LEN. Um pouco antes, em 2005, foi promulgada a Lei 26.058 ou Lei de Educação Técnico Profissional - Lei de ETP que passou a regular e a ordenar a educação técnico-profissional. A nova legislação educativa determinou um pressuposto nacional para a educação técnico-profissional, que gerou diversas iniciativas de melhorias, durante a década seguinte, na oferta pública do ensino médio técnico, o qual comporta um ano a mais de curso. Ocorreu um aumento dos recursos orçamentários e da ênfase dada nos discursos políticos à educação técnica como forma de inclusão social e de desenvolvimento nacional, que se veem refletidos em normativas legais e em programas educacionais. Otero (2014) afirma que a Lei de

\footnotetext{
${ }^{3} \mathrm{Na}$ Argentina, o ensino médio é denominado "educación secundaria" (Lei 26.206, de 2006), mas também se encontra na literatura os termos "nivel secundario" e "secundaria". Anterior a essa lei também encontra-se o termo "nivel medio" ou "polimodal". Neste artigo é adotado o termo ensino médio como alusão à educação secundária, nível secundário, escola secundária e secundária, somado o adjetivo técnico ao se referir ao ensino médio técnico. $\mathrm{O}$ ensino médio argentina, na atualidade, inicia-se com aproximadamente 13 anos e encerra-se com aproximadamente 19 anos no caso do curso técnico, transcorrendo 7 anos de formação, dependendo da região do país conforme autoriza a lei. Inicialmente, pensou-se em centrar os trabalhos apenas no ciclo de escolha da especialidade do curso técnico, os últimos quatro anos do ensino médio técnico (com variações), porém, percebeu-se que o discurso político em torno do ensino médio não se restringe a um ciclo, na Argentina tem essa conformação histórica, ainda que tenham ocorrido tentativas, como nos anos de 1990, de encurtá-lo, dividindo-o em dois ou levando parte para o primário; as quais foram duramente questionadas por parte do movimento sindical e da população.
} 
Denise Bianca Maduro Silva

2019

Fabrício Aparecido dos Santos
Cadernos Prolam/USP, v. 19, n. 35, p. 132-150, Jul./Dez.

DOI: 10.11606/issn.1676-6288.prolam.2019.161974

ETP impulsionou a modernização e a vinculação com a produção e o trabalho, incrementando o investimento em infraestrutura e equipamentos das escolas e centros de formação profissional.

Nesse marco, recuperou-se a Educação Técnico-Profissional, mediante a firme decisão política de dar apoio à inclusão, permanência e finalização das trajetórias formativas dos estudantes, assim como sua inserção em um novo contexto socioprodutivo de país orientado para a industrialização, o emprego e a justiça social. (ARGENTINA, 2015, p. 7, tradução nossa).

No entanto, em se tratando do ensino médio obrigatório, persiste a tensão entre a pretensão republicana igualitarista da escola para todos e a capacidade efetiva de realização desse ideal (DUSSEL, 2009). Na Argentina, a evasão escolar encontrada neste nível de ensino e na modalidade técnica é um grande problema (OTERO, 2011). Conforme Otero (2011), este quadro traz um duplo desafio na educação técnica na Argentina: de um lado, quebra com o esquema jurídico vigente de obrigatoriedade do ensino médio; de outro, apresenta um desafio para a inclusão dos setores mais vulneráveis da população, que viam na educação técnica, historicamente, uma via de acesso a melhores condições de vida.

No sentido de aportar para a análise do problema da evasão escolar no ensino médio técnico argentino, apresentam-se, neste artigo, os dados estatísticos educacionais nacionais para esse nível de ensino no ano de $2015^{4}$, os quais são discutidos em relação a qualidade do dado obtido e desagregados por modalidade (técnica e não técnica), sexo e tipo de oferta (privada e pública), além de contextualizados por meio de 18 entrevistas $^{5}$ com gestores da informação educacional e da educação técnico-profissional ${ }^{6}$. Auxilia nessa discussão a literatura pertinente ao campo de estudos sobre evasão escolar no ensino médio, em especial no ensino médio técnico, a exemplo dos trabalhos produzidos pela Rede Ibero-Americana de Estudos sobre Educação

\footnotetext{
${ }^{4}$ Dados disponibilizados pela Direção Nacional de Informação e Estatística Educativa do Ministério da Educação e Desporto da Nação (DiNIEE) para o ensino médio técnico na Argentina.

5 Foram entrevistas voluntárias, gravadas, transcritas, enviadas aos entrevistados para conferência e, então, categorizadas para análise dos discursos com auxílio do software f4analyse, conforme indicações metodológicas de Creswell, 2007; Yin, 2011; Legard; Keegan; Ward, 2003. O f4analyse auxiliou na classificação e análise sistemática dos dados qualitativos, por meio da seleção, codificação e recuperação de conteúdo mais relevante das entrevistas.

${ }^{6}$ Entrevistas realizadas no primeiro semestre de 2016, em Buenos Aires, para compor tese doutoral, defendida no Programa de Pós-graduação em Educação a Universidade Federal de Minas Gerais, que compara a evasão escolar na educação profissional de Brasil e Argentina entre os anos de 2003 e 2015 (MADURO SILVA, 2018). As abordagens e os instrumentos metodológicos utilizados obedeceram aos procedimentos éticos estabelecidos para a pesquisa científica em Ciências Humanas. Para resguardar o anonimato dos entrevistados, utiliza-se de nomes fantasia.
} 
Profissional e Evasão Escolar (RIMEPES) ${ }^{7}$. Ao fim, logra-se uma leitura neoinstitucionalista histórica (DYE, 2009; HALL; TAYLOR, 2003; IMMERGUT, 2007) dos modos de gestão de política pública encontrados ao se tratar da problemática. Em específico, neste artigo, considera-se que as entrevistas dos gestores sobre a qualidade dos dados relativos à evasão escolar no ensino médio técnico auxilia a desvelar um modo de gestão da temática no âmbito das políticas públicas educacionais na Argentina.

Os estudos aqui apresentados apontam que as políticas de desenvolvimento da educação técnica, delineadas a partir da Lei de ETP e da LEN, apesar de buscarem sua maior democratização, seguem apresentando limites estruturais com efeitos para a efetiva conclusão das trajetórias educativas na Argentina.

Ademais, trazer luz ao tema da obrigatoriedade e da evasão escolar no ensino médio técnico possibilita reflexões sobre a perspectiva economicista dos discursos nas políticas educacionais no âmbito da América Latina para esta etapa da educação básica.

\section{O PROBLEMA DOS DADOS ESTATIISTICOS}

A produção de dados sistematizados sobre evasão escolar no ensino médio técnico é um problema a ser enfrentado na Argentina. E obter uma base de dados confiáveis sobre evasão escolar no ensino médio técnico argentino é um desafio. Durante a consecução do trabalho de campo para tese doutoral (MADURO SILVA, 2018), em Buenos Aires, na Argentina, foram utilizadas informações da Direção Nacional de Informação e Estatística Educativa do Ministério da Educação e Desporto da Nação (Dirección Nacional de Información y Estadística Educativa do Ministerio de Educación y Deportes de la Nación) (DiNIEE), responsável pela produção de dados estatísticos para a educação.

\footnotetext{
${ }^{7}$ http://www.fae.ufmg.br/rimepes/objetivos_gerais.html. Acesso em: 16 nov. 2017. Santos (2017), em estado da arte sobre as investigações em evasão escolar na educação profissional, encontrou que aproximadamente $80 \%$ de toda a produção acadêmica no Brasil sobre o tema encontra-se no âmbito da RIMEPES.
} 
O problema com relação à qualidade dos dados se inicia com a falta de uma base que permita contabilizar a evasão escolar a partir do registro dentro da instituição de ensino e em sua totalidade na nação. Em entrevista concedida em 2016, um dos técnicos responsáveis pela produção e análise dos dados nacionais para educação, relatou que já estava em processo essa migração de informações, para consolidar uma base nacional informatizada e única, e que permitisse contabilizar os registros individualmente.

\begin{abstract}
Nós tivemos que migrar todo nosso sistema estatístico, arcaico, para um que é completamente on line e que é por aluno. A discussão interna é se isso tem que ser parte de um sistema de gestão escolar ou não. Se isso tem que ser parte do sistema com o qual o secretário subsidia as assistências ou faz seus trabalhos cotidianos ou tem que ser algo independente. Porém, mais além disso, é muito boa ideia poder incorporar um indicador. Ou seja, "este garoto em qualquer momento vai ir embora". (Estatísticas. Entrevista concedida a Maduro Silva, 2018, p. 219).
\end{abstract}

Outro problema central para as estatísticas nacionais é que o instrumento utilizado para capturar as informações chega apenas àqueles que estão na escola, não permitindo o acompanhamento da trajetória dos evadidos. Para o entrevistado, o problema dos dados em educação é que eles vão até a escola, e não ao indivíduo, e somente se referem aos que estão dentro do sistema. As medidas existentes não captam, dessa forma, a evasão escolar no sistema de ensino.

O tema do problema dos dados que nós temos aqui, como te dizia, são dados agregados. Não são caso por caso e são só de alunos que estão estudando. Essa é a limitação. Não temos os dados dos que não estão. Então, não temos $100 \%$ para estabelecer as porcentagens. Temos que ir buscar fontes de dados externos (o censo, por exemplo), ter populações na idade, tomar do censo e compará-las com os dados nossos de matrícula. Porém, não surge de nosso próprio levantamento, pelo problema este que te disse, que é lógico. Digamos: nós aqui só estamos levantando informação dos que estão dentro do sistema, não dos que estão fora do sistema, porque não estão na escola. Nosso questionário vai à escola... (Estatísticas. Entrevista concedida a Maduro Silva, 2018, p. 219).

Sim, o que passa, é que quando você está tratando de medir muito fino isso não é.... Como te digo? É como tratar de medir centímetros com uma régua marcada a cada 10 centímetros. Não consegue. Coloca muito mais ruído do que o que você quer medir. (Estatísticas. Entrevista concedida a Maduro Silva, 2018, p. 220). 
Em particular, os alunos que saem sem passe (salidos sin pase $e^{8}$ ) constituem a categoria das estatísticas nacionais escolares que mais se aproxima da medida dos alunos em situação de abandono, pois refere-se àqueles que de um ano para o outro não se registraram para dar continuidade aos estudos nem na própria instituição de ensino nem solicitaram transferência para outra. No entanto, para o entrevistado, é uma medida que apresenta graves problemas, porque, ao se relacionar a matrícula de alunos com a distribuição de recursos e a autorização e condições de funcionamento dos estabelecimentos escolares, como é feito na Argentina, esse número de matrícula inicial pode estar superestimado e os de abandono subestimados

Não está muito claro. Há um problema com os alunos sem passe [...], é uma hipótese que se trabalha aqui: as escolas informam mais matrículas que têm. Se têm 15, informam 20 , porque têm medo de que a partir dessa informação, fechem seus cursos. (Estatísticas. Entrevista concedida a Maduro Silva, 2018, p. 220)

Como afirma LaPlante (2014), um dos principais problemas encontrados para se tratar a evasão deriva do fato de que os mecanismos de financiamento por aluno vinculam-se por matriculá-lo no início do ano, mas não por retê-lo e educá-lo. Assim, a informação sobre os estudantes evadidos não chega nem a ser mencionada, gerando muitas vezes um subregistro da evasão escolar nos sistemas de ensino. Quando não se admite o problema, tratá-lo torna-se algo muito mais difícil.

Ademais, a dificuldade para se medir a evasão escolar no ensino médio técnico argentino é aumentada pelo fato das províncias terem momentos distintos de corte entre a primária e o ensino médio, mas também entre o ciclo básico e o ciclo de especialidade técnica dentro do próprio ensino médio técnico.

Em outro âmbito de gestão da informação educacional da nação argentina, no Instituto Nacional de Educação Tecnológica (INET) do Ministério da Educação, um órgão criado para atuar especificamente na educação técnico-profissional ${ }^{9}$, a construção de um sistema próprio de

\footnotetext{
${ }^{8}$ Opta-se neste trabalho em utilizar o termo em espanhol e informado pela DiNIEE. Trata-se dos alunos que saem do sistema sem um lastro e sem terminar o percurso do ensino médio técnico.

${ }^{9}$ O Ministério de Educação e Justiça da Nação (Ministerio de Educación y Justicia de la Nación) criou escolas técnicas e de formação em ofícios. Paralelamente criou organismos especializados para condução e supervisão das escolas. Pelo Decreto 14538/44, criou-se a Comisión Nacional de Aprendizaje y Orientación Profesional (CNAOP) que, posteriormente, se fundiu à Dirección Nacional de Enseñanza Técnica, dando origem ao Consejo Nacional de Educación Técnica (CONET), criado como uma autarquia, mediante a Lei 15.240, de 1959. Dando continuidade aos
} 
Denise Bianca Maduro Silva

2019

Fabrício Aparecido dos Santos
Cadernos Prolam/USP, v. 19, n. 35, p. 132-150, Jul./Dez.

DOI: 10.11606/issn.1676-6288.prolam.2019.161974

monitoramento e avaliação da educação profissional capaz de dizer da evasão escolar, também é uma questão pendente, como demonstra o depoimento de gestores do órgão. O primeiro sobre sua experiência a princípio dos anos 2000:

[...] quando eu comecei [...], ríamos porque não tínhamos um dado sequer. Estatísticas oficiais davam qualquer coisa... Então, fizemos uma piada, sobre tratar de identificar as escolas. Há um hino dos estudantes: "sobre aqueles que somos, que fomos e para sempre seremos estudantes". É um hino clássico na Argentina que cantam os estudantes quando terminam o ensino médio. Então, dizíamos: "Apliquem o hino dos estudantes para as escolas técnicas". Aquelas que foram, que seguiram sendo nos anos 1990, aqueles que foram e deixaram de ser e as que seguem sendo, porém perderam o contraturno, que perderam as oficinas. (Dirigente 1. Entrevista concedida a Maduro Silva, 2018, p. 218).

O segundo gestor do INET, citado abaixo, já em 2016, aponta a permanência do problema:

Temos muitas políticas e pouco medido, porque o que dizem é que é muito difícil medir o fator do abandono. Agora se está fazendo um grande esforço para ter coleta de dados quantitativos para poder fazer um estudo qualitativo: o INET está atravessando esse processo agora. Estamos em um grande esforço de captura de dado quantitativo para poder fazer estudos qualitativos. E nos estaria faltando, justamente, o estudante que abandona. É muito volátil! (Dirigente 2. Entrevista concedida a Maduro Silva, 2018, p. 221).

Tendo em consideração as observações acima sobre o sistema de informações disponível sobre a educação profissional na Argentina, expõem-se a seguir os dados obtidos da DiNIEE para o ano de 2015 sobre os registros acadêmicos dos alunos do ensino médio nas escolas técnicas e não técnicas de Argentina.

trabalhos do CONET, que foi fechado nos anos de 1980, nos anos de 1990 surgiu o INET, responsável pelo desenho, implementação e acompanhamento das políticas nacionais para educação técnica-profissional, mas sem ter uma rede própria de escolas técnicas sob sua coordenação e, até as mudanças a partir de 2003, esvaziado de capacidade organizativa (OTERO, 2014). 
Denise Bianca Maduro Silva 2019

Fabrício Aparecido dos Santos
Cadernos Prolam/USP, v. 19, n. 35, p. 132-150, Jul./Dez.

DOI: 10.11606/issn.1676-6288.prolam.2019.161974

\section{EVASÃO ESCOLAR NO ENSINO MÉDIO TÉCNICO ARGENTINO}

Destaca-se (Figura 1) que há diferença entre escolas estatais e escolas privadas, em grande medida, pela proporção de matrículas, muito mais numerosas na rede pública do que na privada, correspondendo no ano de 2015 a 2.807 .032 (68\%) e 1.139 .391 (32\%), de um total de 3.946 .423 matrículas. 90\% de todas as escolas do ensino médio técnico são estatais na Argentina. O maior número de matrículas no ensino médio técnico de gestão estatal foi justificado pelos gestores entrevistados por ser o investimento em escolas técnicas muito oneroso para ser suportado pelas partes privadas, excetuando casos de grupos empresariais (MADURO SILVA, 2018). Este dado justifica o olhar mais detido na escola pública argentina ao final da seção, ao se discutirem os fatores acadêmicos relacionados à evasão escolar (repetência, defasagem idade-série, "salidos sin pase" e egressos).

Figura 1 - Matrículas no ensino médio na Argentina por modalidade e tipo de oferta, ano de $2015^{10}$

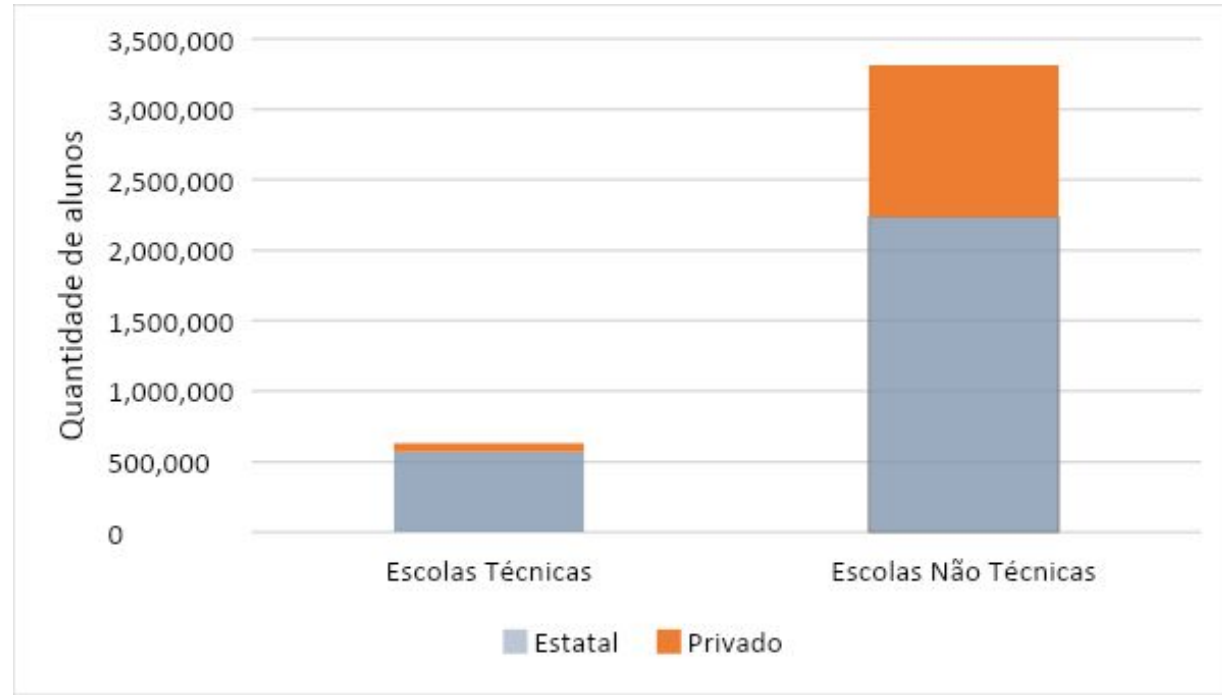

Fonte: Relevamiento Anual 2015. DiNIEE. Ministerio de Educación - Argentina. Data: 02/06/2016.

10 Nota: "Escolas técnicas" correspondem a instituições de nível médio constantes, e "escolas não técnicas" a instituições de nível médio não constantes no Registro Federal de Instituciones de Educación Técnico Profesional RFIETP em 30/06/2013. 
Em sequência, apresentamos os dados referentes às escolas técnicas e não técnicas, separando entre sexos e entre escolas de gestão estatal e privada, relacionando aos fatores acadêmicos de repetência, defasagem idade-série, "salidos sin pase" e egressos. Dá-se destaque aos dados de alunos repetidores e em defasagem idade-série para o nível médio de ensino por serem estes fatores fortemente relacionados nas pesquisas da área como causas da evasão escolar (FRITSCH, VITELLI, ROCHA, 2014).

Nas escolas de ensino médio técnico, estão matriculados 632.070, onde 204.160 (32\%) são mulheres e 427.910 (68\%) homens. Do total de matrículas, 569.800 (90\%) estão no setor estatal e 62.270 (10\%) no setor privado. E dentro desse número de matriculados, temos 59.315 alunos repetentes, sendo 16.421(38\%) mulheres e 42.894 (62\%) homens, onde 57.475 (97\%) no setor estatal e 1.840 (3\%) no setor privado.

O total de matrículas no ensino médio não técnico foi 3.314.353, sendo 2.237.232 (68\%) dentro do setor estatal e 1.077.121 (32\%) no setor privado. Em relação a sexo, 1.790 .630 (54\%) mulheres e 1.523.723 (46\%) homens fizeram matrícula neste ano de 2015. Quando analisados os dados de repetição de ano, aqueles da escola não técnica, conformam 291.018 matrículas, sendo 127.906 (44\%) mulheres e 163.112 (56\%) homens. Do total de repetidores, 254.515 (87\%) estão no setor estatal e 36.503 (13\%) no setor privado.

A existência de alunos em defasagem idade-série também é um fator comum, seja na rede estatal ou privada de ensino: na esfera estatal com 1.150 .088 (88\%) alunos e na esfera privada com 162.040 (12\%) alunos, de um total d e 1.312.128. Quando se olha apenas para alunos em defasagem idade-série em escolas técnicas de nível médio, são 198.240 (95\%) estudantes na gestão estatal enquanto 8.399 (5\%) na gestão privada, de um total de 206.639. Já nas escolas não técnicas de nível médio, o número de alunos em defasagem idade-série totaliza 1.105.489, sendo 951.848 (86\%) matrículas de gestão estatal e 153.641 (14\%) de gestão privada.

Outra categoria de dados disponibilizados refere-se a "salidos sin pase", alunos que saíram da escola média sem registro de transferência para outra instituição e sem terminarem os estudos referentes ao ensino médio, um conceito que se aproxima ao de evasão escolar, mas que não abarca todas as situações passíveis de leitura e registro sob esse signo; um problema comum ao se tratar do tema da evasão escolar, um conceito complexo e multifacetado. 
Denise Bianca Maduro Silva

2019

Fabrício Aparecido dos Santos
Cadernos Prolam/USP, v. 19, n. 35, p. 132-150, Jul./Dez.

DOI: 10.11606/issn.1676-6288.prolam.2019.161974

A evasão escolar tem sido associada a situações muito diversas. Pode-se referir à retenção e repetência do aluno na escola; à saída do aluno da instituição; à saída do aluno do sistema de ensino; a não conclusão de um determinado nível de ensino; ao abandono da escola e posterior retorno. Abrange indivíduos que nunca ingressaram em um determinado nível de ensino, especialmente na educação compulsória, bem como o estudante que conclui uma etapa do ensino, mas se comporta como um dropout (DORE; LÜSCHER, 2011, p. 150).

Existem estudos que articulam os dados sobre evasão escolar de forma longitudinal e em relação com outras bases (NARODOWSKI, 2014), apresentando valores substancialmente diferentes aos descritos neste artigo para os alunos "salidos sin pase" que exibe uma frequência anual. Optou-se, no entanto, por apresentar esses números por dizerem, ainda que de forma parcial, do abandono encontrado nesse sistema de ensino.

Para 2015, foram 112.796 alunos "salidos sin pase", sendo 51.776 (46\%) mulheres e $61.020(54 \%)$ homens. No setor estatal, os "salidos sin pase" são 105.065 (93\%) e no setor privado, 7.731 (7\%). Nas escolas técnicas de nível médio, foram 21.558 "salidos sin pase", onde 7.749 (36\%) são mulheres e 13.809 (64\%) homens; por outra perspectiva 20.739 do setor estatal e 819 do setor privado.

No ensino médio não técnico, foram 91.238 alunos "salidos sin pase", sendo 44.027 (48\%) mulheres e 47.211 (52\%) homens. Do total, 84.326 (92\%) estavam em escolas de gestão estatal, já no setor privado foram 6.912 (8\%) “salidos sin pase”.

$\mathrm{Na}$ escola técnica de nível médio, o número de egressos para 2015 foi de 45.267 alunos, 15.207 (34\%) mulheres e 30.060 (66\%) homens, 38.996 (86\%) em escolas estatais. Nas escolas não técnicas, o total de egressos foi de 278.971 estudantes, sendo 171.438 (61\%) mulheres e 107.533 (39\%) homens, e, ainda, 161.104 (58\%) em escolas estatais e 117.867 (42\%) em escolas privadas. 
A Tabela 1, sintetiza os dados acima apresentados.

Tabela 1 - Modalidade de ensino por sexo e gestão, relacionados aos fatores acadêmicos

\begin{tabular}{|c|c|c|c|c|c|c|c|c|}
\hline & \multicolumn{3}{|c|}{ Ensino médio não técnico } & \multicolumn{5}{c|}{ Ensino médio técnico } \\
\cline { 2 - 10 } & Pública & Privada & Mulher & Homem & Pública & Privada & Mulher & Homem \\
\hline Repetência & 254,515 & 36,503 & 127,906 & 163,112 & 57,475 & 1,840 & 16,421 & 42,894 \\
\hline $\begin{array}{c}\text { Defasagem } \\
\text { idade-série }\end{array}$ & 254,516 & 36,504 & & & 57,476 & 1,841 & & \\
\hline $\begin{array}{c}\text { Salidos } \\
\text { sin pase" }\end{array}$ & 254,517 & 36,505 & 44,027 & 47,211 & 57,477 & 1,842 & 7,749 & 13,809 \\
\hline Egressos & 254,518 & 36,506 & 171,438 & 107,533 & 57,478 & 1,843 & 15,207 & 30,600 \\
\hline
\end{tabular}

Fonte: Elaborado pelos autores em base a Relevamiento Anual 2015. DiNIEE. Ministerio de EducaciónArgentina. Data: 02/06/2016.

$\mathrm{Na}$ terceira parte desta seção, discutimos detidamente os fatores acadêmicos (repetência, defasagem idade-série, "salidos sin pase" e egressos) para a escola pública argentina de nível médio, responsável por $90 \%$ da oferta na modalidade técnica e $68 \%$ da não técnica. A Figura 2 mostra os fatores acadêmicos no ensino médio em escolas técnicas e não técnicas em 2015, considerando o valor total para a soma dos referidos fatores. Os dados aqui apresentados não mostram uma diferença significativa entre os índices avaliados na comparação entre escolas técnicas e escolas não técnicas. Essa proximidade indica que os problemas relativos a repetência, defasagem idade-série, "salidos sin pase" e formação de egressos enfrentados pelas escolas de nível médio na Argentina são comuns tanto às escolas técnicas como não técnicas, o que corrobora com Fanfani (2010) que identifica a escola de nível médio na Argentina, técnica ou não técnica, como meio de seleção. Especificamente para o ensino médio técnico, em tese doutoral MADURO SILVA (2018) encontra em entrevista aos gestores da educação profissional na Argentina que a evasão da escola técnica é naturalizada em um discurso de manutenção da qualidade e legitimada pelo discurso da falta de vocação dos alunos, responsabilizando o indivíduo, sem questionamento dos fatores institucionais relacionados à evasão escolar. 
Denise Bianca Maduro Silva 2019

Fabrício Aparecido dos Santos
Cadernos Prolam/USP, v. 19, n. 35, p. 132-150, Jul./Dez.

DOI: 10.11606/issn.1676-6288.prolam.2019.161974

Figura 2 - Fatores acadêmicos por modalidade no ensino médio em 2015 na Argentina ${ }^{11}$

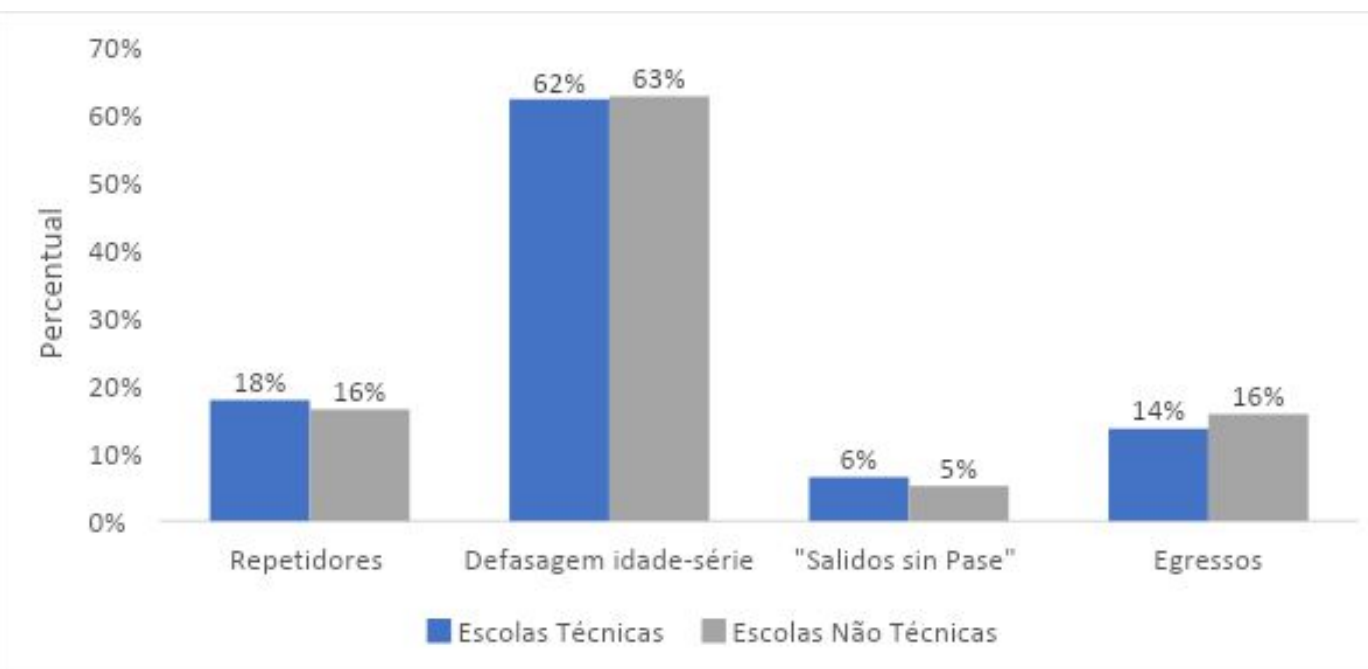

Fonte: Relevamiento Anual 2015. DiNIEE. Ministerio de Educación - Argentina. Data: 02/06/2016.

A Figura 3 mostra os fatores acadêmicos ${ }^{12}$ de repetência, "salidos sin pase" e egressos no ensino médio em escolas técnicas e não técnicas em 2015 na comparação entre os sexos, considerando o valor total para a soma dos referidos fatores. Na figura 3, a proporção encontrada para os fatores acadêmicos entre escolas técnicas e não técnicas para 2015 não difere muito quando se faz a comparação entre os sexos. Tanto na escola técnica como na não técnica os homens repetiram mais, aproximadamente 7 e 14 pontos percentuais a mais em relação às mulheres da escola técnica e não técnica, respectivamente. Também egressaram menos, com 16\% a menos que as mulheres na escola não técnica, enquanto que na escola técnica essa diferença ficou em $4 \%$. Os valores apresentados para homens nas categorias repetidores, "salidos sin pase" e egressos não apresentam diferenças significativas na comparação entre escolas técnicas e não técnicas.

${ }^{11}$ Nota: "Escolas técnicas" correspondem a instituições de nível médio constantes, e "escolas não técnicas" a instituições de nível médio não constantes no Registro Federal de Instituciones de Educación Técnico Profesional RFIETP em 30/06/2013.

${ }^{12}$ Não foram fornecidos dados de alunos em defasem idade-série distribuídos por sexo. 
As mulheres da escola técnica apresentam um resultado pior do que as mulheres da escola não técnica: repetem mais, com uma diferença aproximada de 5 pontos percentuais, egressam menos, com uma diferença aproximada de 11 pontos percentuais, e apresentam mais ocorrências de "salidos sin pase", com uma diferença aproximada de 7 pontos percentuais. De fato, nesta última categoria, "salidos sin pase", apresentam mais ocorrências inclusive do que os homens da escola técnica, em aproximadamente 4 pontos percentuais. Esses resultados enfatizam a necessidade de se pensar a inclusão das mulheres na escola técnica para sua maior permanência e êxito.

Figura 3 - Fatores acadêmicos por modalidade e sexo no ensino médio em 2015 na Argentina ${ }^{13}$

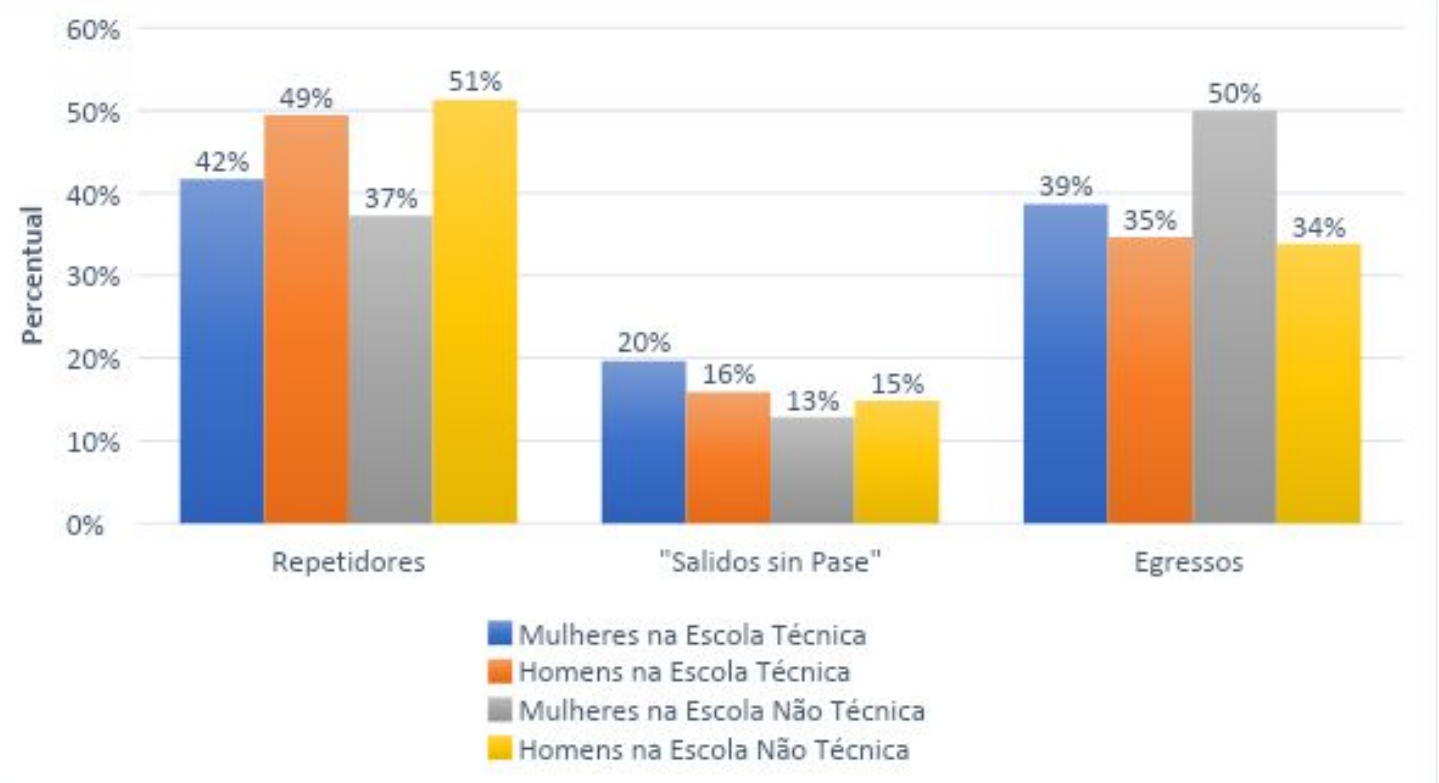

Fonte: Relevamiento Anual 2015. DiNIEE. Ministerio de Educación - Argentina. Data: 02/06/2016.

$\mathrm{Na}$ Figura 4, percebe-se que os homens predominam no ensino médio técnico argentino. A falta de políticas dirigidas à inclusão das mulheres serve para perpetuar seu afastamento das carreiras técnicas e estimular a manutenção dos papéis sociais dos homens e das mulheres na sociedade argentina (SEOANE, 2014). Como as entrevistas contextualizam, a falta de políticas

13 Nota: "Escolas técnicas" correspondem a instituições de nível médio constantes e "escolas não técnicas" a instituições de nível médio não constantes no Registro Federal de Instituciones de Educación Técnico Profesional RFIETP em 30/06/2013. 
Denise Bianca Maduro Silva 2019

Fabrício Aparecido dos Santos
Cadernos Prolam/USP, v. 19, n. 35, p. 132-150, Jul./Dez.

DOI: 10.11606/issn.1676-6288.prolam.2019.161974

públicas inclusivas e de assistência institucional às adolescentes e jovens mulheres na educação técnica, aliada à questão cultural, influencia negativamente tanto em sua escolha pela modalidade quanto em sua permanência.

Figura 4 - Matrículas no nível médio na Argentina em 2015 por modalidade e sexo ${ }^{14}$

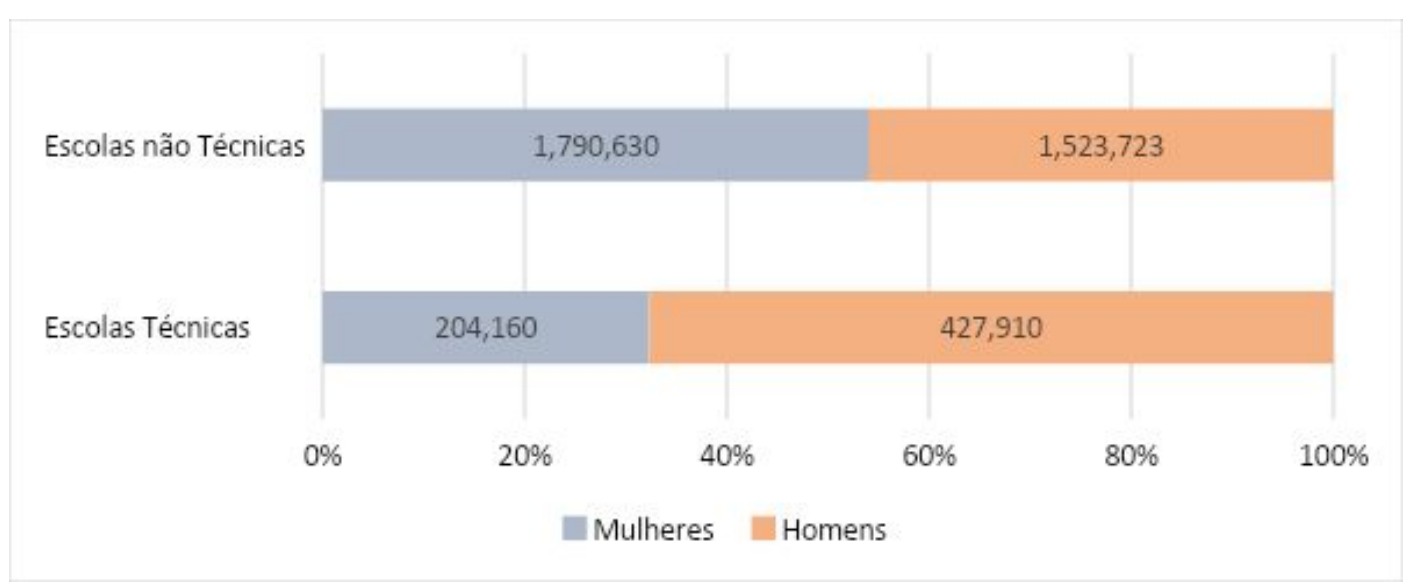

Fonte: Relevamiento Anual 2015. DiNIEE. Ministerio de Educación - Argentina. Data: 02/06/2016.

\section{CONSIDERAÇÕES FINAIS}

De forma geral, a diferença dos percentuais encontrados para escolas técnicas e não técnicas não é significativa nos itens repetência, defasagem idade-série, "salidos sin pase" e egressos levantados para 2015 na Argentina, apontando que os fatores acadêmicos elencados, relacionados à evasão escolar, são problemas comuns às duas modalidades neste nível de ensino. No entanto, na escola pública, quando os fatores acadêmicos são desagregados por modalidade e sexo, observamos:

- Os homens apresentam o maior índice de repetência e menor índice de egressos nas escolas técnicas do que nas escolas não técnicas. Os homens apresentam maior índice de

\footnotetext{
${ }^{14}$ Nota: "Escolas técnicas" correspondem a instituições de nível médio constantes e "escolas não técnicas" a instituições de nível médio não constantes no Registro Federal de Instituciones de Educación Técnico Profesional RFIETP em 30/06/2013.
} 
repetência e menor índice de egressos em relação às mulheres nas escolas técnicas e nas não técnicas.

- Os problemas de repetência e "salidos sin pase" são maiores e o percentual de egressos é menor para as mulheres na escola técnica do que na escola não técnica.

A obrigatoriedade da escola média e a ênfase na modalidade técnica a partir da segunda metade dos anos de 2000 na Argentina pôs em evidência a importância da permanência nos estudos. Para ampliar a oferta escolar e garantir as condições sociais de aprendizado de todos, o Estado se viu obrigado a formular políticas para evitar a evasão de estudantes, porém, foram medidas de cunho focalizado e que não garantiram que todos completassem esse nível de ensino, etapa final da educação básica. $\mathrm{O}$ crescimento das matrículas teve como retorno altos índices de abandono e de repetência entre os jovens do ensino médio técnico: foram incluídos, mas sem inclusão.

Com os dados aqui apresentados e confrontados com as entrevistas, constatou-se que ainda estão em processo de desenvolvimento sistemas de informação capazes de trazer a medida da evasão escolar no ensino médio técnico e ainda falta identificar a real influência dos fatores escolares a ela associados. Sem informações sistematizadas, o discurso em torno dos fatores associados à evasão escolar pode trabalhar em prol de preconcepções de enraizamento histórico a respeito do ensino médio técnico - como seu mandato seletivo e questões de gênero influenciando o discurso sobre as iniciativas formuladas, negadas ou invisibilizadas no combate à evasão escolar no ensino médio técnico.

\section{REFERÊNCIAS}

ARGENTINA. Ley n ${ }^{\circ}$ 26.206. Ley de Educación Nacional de la Argentina. Sancionada: 14 dez. 2006. Promulgada: 27 dez. de 2006. Buenos Aires. Disponível em: $<$ http://www.me.gov.ar/doc pdf/ley de educ_nac.pdf $>$. Acesso em: 13 nov. 2017. 
ARGENTINA. Ley no 26.058. Ley de Educación Técnico Profesional. Sancionada: 7 set. de 2005. Promulgada: 8 set. de 2005. Buenos Aires. Disponível em: $<$ http://www.me.gov.ar/doc_pdf/ley26058.pdf>. Acesso em: 15 nov. 2017.

ARGENTINA. Ministerio de Educación. Instituto Nacional de Educación Tecnológica. La técnica ganada. Conmemoración de los 10 años de la Ley de Educación Técnico Profesional. Buenos Aires: Ministerio de Educación de la Nación, 2015g, 35p.

ARGENTINA. Ministerio de Educación. Instituto Nacional de Educación Tecnológica. Disponível em: $<$ http://www.inet.edu.ar/index.php/institucional/historia/ >. Acesso em: $01 \mathrm{dez}$. 2017.

CHOULIARAKI, L.; FAIRCLOUGH, N. Discourse in Late Modernity: rethinking critical discourse analysis. Edinburgh: Edinburgh University Press , 1999, 168 p.

CRESWELL, J. W. Procedimentos qualitativos. In: CRESWELL, J. W. Projeto de pesquisa: métodos qualitativo, quantitativo e misto. 2. ed. Porto Alegre: Artmed, 2007. p. 184-210.

DORE, R.; LÜSCHER, A. Z. C. Política educacional no Brasil: educação técnica e abandono escolar. RBPG, Brasília, supl. 1, v. 8, p. 147-176, dez. 2011.

DUSSEL, I. La escuela media y la producción de la desigualdad: continuidades y rupturas. In: TIRAMONTI, G.; MONTES, N (Comp.). La escuela media en debate: problemas actuales y perspectivas desde la investigación. Buenos Aires: Manantial/FLACSO, $1^{\text {a }}$ ed. 2009. p. 39-52.

DYE, T. R. Cap. 3: Mapeamento dos modelos de análise de políticas públicas. In: HeidemanM, F. G.; SALM, J. F. (Org.) Políticas públicas e desenvolvimento: bases epistemológicas e modelos de análise. Brasília: EDU-UNB, 2009.

FANFANI, E. T. Los que ponen el cuerpo: el profesor de secundaria en la Argentina actual. Educar em Revista, Curitiba, n. 1, p. 37-76, 2010.

FRITSCH, R.; VITELLI, R.; ROCHA, C. Para que jovens? Que políticas? - perfil de alunos ingressantes no ensino médio e políticas educacionais. In: DORE, R.; ARAÚJO, A. C; MENDES, J. S. (Org.). Evasão na educação: estudos, políticas e propostas de enfrentamento. Brasília: Instituto Federal de Brasília, 2014. 131-162. 
HALL, P. A.; TAYLOR, R. C. R. As três versões do neo-institucionalismo. Lua Nova, n. 58, p. 193-223, 2003.

IMMERGUT, E. O núcleo teórico do novo institucionalismo. Tradução de Paulo Cézar Nascimento. In: SARAIVA, E.; FERRAREZI, E. Políticas Públicas. Coletânea v. 1, p. 155-195, 2007.

LAPLANTE, M. D. A epidemia da evasão escolar nos Estados Unidos: estratégias com impacto sobre a melhoria dos índices de formação e de oportunidades para manter viva a luta para acabar com a epidemia da evasão escolar. In: DORE, R.; ARAÚJO, A. C; MENDES, J. S. (Org.). Evasão na educação: estudos, políticas e propostas de enfrentamento. Brasília: Instituto Federal de Brasília, 2014. p. 437- 462.

LEGARD, R.; KEEGAN, J.; WARD, K. In-depth interviews. In: RITCHIE, J.; LEWIS, J. (Org.). Qualitative research practice: a guide for social science students and researchers. London: Sage, 2003. p. 138-169.

MADURO SILVA, D. Estudo comparado sobre evasão escolar na educação profissional Brasil e Argentina. 2018, 344p. Tese (Doutorado em Educação) - Faculdade de Educação, Universidade Federal de Minas Gerais, Belo Horizonte, 2018.

NARODOWSKI, M. El abandono en la escuela media en la Argentina (2004-2014). Buenos Aires: I+E Instituto de Investigación y Educación Económica, 2016. Mimeografado.

OTERO, A. Educación técnico profesional, política y gestión de la modalidad para el caso argentino. In: DORE, R.; ARAÚJO, A. C; MENDES, J. S. (Org.). Evasão na educação: estudos, políticas e propostas de enfrentamento. Brasília: Instituto Federal de Brasília, 2014. p. 57-76.

OTERO, A. Escuela media y abandono escolar en Argentina: aproximaciones a un debate pendiente. Educação em Revista, Belo Horizonte, v. 27, n. 3, dez. 2011. Disponível em: $<\mathrm{http}: / /$ www.scielo.br/scielo.php?script=sci_arttext\&pid=S0102-46982011000300008 $>$. Acesso em: 17 nov. 2017.

SANTOS, T. A. Evasão e permanência na educação profissional técnica de nível médio do PRONATEC no Instituto Federal de Educação, Ciência e Tecnologia de Minas Gerais. 
2017. 231 f. Dissertação (Mestrado em Educação Tecnológica) - Centro Federal de Educação Tecnológica de Minas Gerais (CEFET-MG), Belo Horizonte, 2017.

SEOANE, V. Experiencias de jóvenes mujeres de escuelas técnicas en la producción de géneros, sexualidades y disciplinas. In: VILLA, A. I.; MARTÍNEZ, M. E. (Comp.). Relaciones escolares y diferencias culturales, la educación en perspectiva intercultural. Buenos Aires: Centro de Publicaciones Educativas y Material Didáctico, 2014a. Cap. 4, p. 103-130.

YIN, R. K. Interviewing. In: YIN, R. K. Qualitative research from start to finish. New York: The Guilford Press, 2011. p. 132-142. 